\title{
The influential factors on very high cycle fatigue testing results
}

\author{
PENG Wen-jie* XUE Huan** GE rui PENG zhou \\ Wuhan Branch of Baosteel Central Research Institute \\ (R\&D Center of Wuhan Iron \& Steel Co.,Ltd. ), Wuhan 430080, China
}

\begin{abstract}
When the fatigue cycle is extended from high cycle $\left(10^{5} \sim 10^{7}\right)$ to very high cycle $\left(10^{7} \sim 10^{9}\right)$, the fatigue testing results will be more sensitive to the influential factors such as specimen size, specimen surface roughness and the inclusion size. The influential factors on the very high cycle fatigue testing results are investigated in the present paper. Firstly, the design and control method for ultrasonic fatigue test were introduced for several specimen shapes. The effect of the shape, size and the surface roughness of specimen on the ultrasonic fatigue test results are investigated. Meanwhile, the effect of test frequency and the size of the inclusion on the fatigue test results are also investigated. It is concluded that: 1 . the test results of specimen with different shape and size differ with each other, due to the risk volume is different. 2. There is a critical roughness for the specimen, depending on the hardness of tested metallic material. A larger roughness than the critical one will lead to a premature fracture. 3. The frequency effect is obvious for the low strength steel, however, is prone to vanish for the very high strength steel. 4 . The very high cycle fatigue will be more sensitive to the inclusion size as the strength increases and the $S / N$ curve character is strongly related to the size of the inclusion.
\end{abstract}

KEY WORDS: Very high cycle fatigue; size effect; frequency effect; inclusion size; surface roughness

\section{Introduction}

In industrial applications, many components are subjected to high-frequency, low-amplitude, very high cycle loading $\left(10^{8}, 10^{9}\right.$ or $\left.10^{10}\right)$ in their working service ${ }^{[1-4]}$. Traditional $10^{7}$ fatigue testing can't meet actual requirements. In order to investigate the fatigue properties of the components failure in very high cycle regime, ultrasonic fatigue test system had been developed and it offers an alternative and effective method for very high cycle fatigue testing ${ }^{[5-6]}$.

For low cycle (LCF) and high cycle fatigue (HCF), the applied stress is relatively high and the failure is prone to initiate from surface. However, for very high cycle fatigue (VHCF), the cracks tend to start at internal defects or inclusions ${ }^{[7-8]}$. Consequently, the test results are more sensitive to the specimen size and the surface roughness. Meanwhile, when the fatigue cycle extends from high cycle to very high cycle, the fatigue property will be mainly related to the defect size of the specimen and the size of the defect will affect the $S-N$ curve characteristics. Furthermore, when the fatigue frequency increased from usual frequencies to ultrasonic frequency, applying the ultrasonic test results directly may lead to unsafe results.

Therefore, in the present paper, a lot of fatigue experiments are conducted to investigate the effect of the specimen shape, size, surface roughness and loading

Corresponding author, *E-mail: pengwenjie@baosteel.com,**E-mail: xue_huan@baosteel.com 
frequency on the test results. Besides, the relationship of the size of defect and the $S-N$ curve characteristics are validated through the fatigue test results and the fracture surface scanning via SEM.

\section{The design of the ultrasonic fatigue specimen}

For ultrasonic fatigue machine, the vibration of the specimen is induced by a piezo-ceramic converter, which generates acoustical waves in the specimen through a power concentrator (horn) to obtain desired displacement and an amplification of the stress. The ultrasonic fatigue specimen must meet the condition of resonance with the experimental system.

Assuming the specimen axis is $x$ axis, $U(x, t)$ is the longitudinal displacement of the section of the specimen at the $t$ time, the resonant length of an ultrasonic fatigue specimen can be derived.

One-dimensional longitudinal wave equation is:

$\frac{\partial^{2} U(x, t)}{\partial t^{2}}=\frac{E}{\rho}\left(\frac{\partial^{2} U(x)}{\partial x^{2}}+\frac{S^{\prime}(x)}{S(x)} \frac{\partial U(x, t)}{\partial x}\right)$

Assuming the specimen meeting the resonance condition, $U(x, t)$ can be separated as $U(x, t)=U(x) \mathrm{e}^{i w t}$, Eq.1 can be rewritten as:

$$
\frac{\partial^{2} U(x)}{\partial x^{2}}+P(x) \frac{\partial U(x)}{\partial x}+k^{2} U(x)=0
$$

Where, $U(x)$ is the displacement formation of the specimen, $P(x)=\frac{S^{\prime}(x)}{S(x)} ; k=\frac{\omega}{c}, c$ is the speed of the ultrasonic wave, $c=\sqrt{\frac{E}{\rho}}, E$ is the tensile modulus; $\omega=2 \pi f, f$ is the frequency of the testing system.

Four different shape specimens are shown in Fig.1. The analytical solution of resonant length can be obtained according to the boundary conditions, continuity condition and the formation of the specimen cross section. The stress distribution and the maximum stress can be obtained via the derivative of the displacement function [9-10].

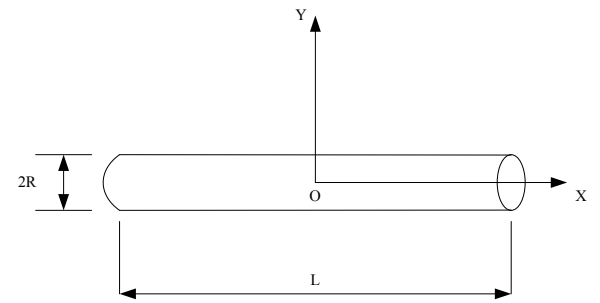

Fig.1a. Constant cross-section specimen

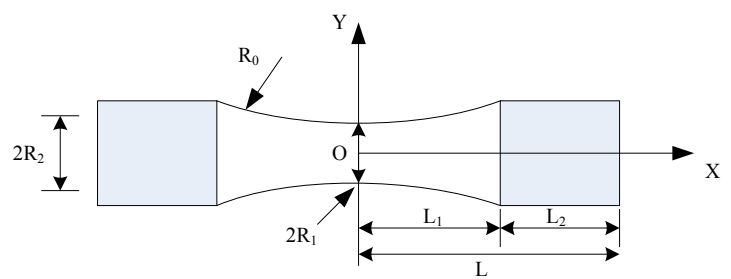

Fig.1b. Sandglass specimen

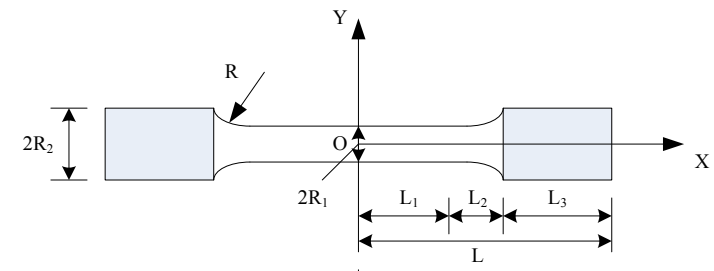

Fig.1c. Dog-bone specimen

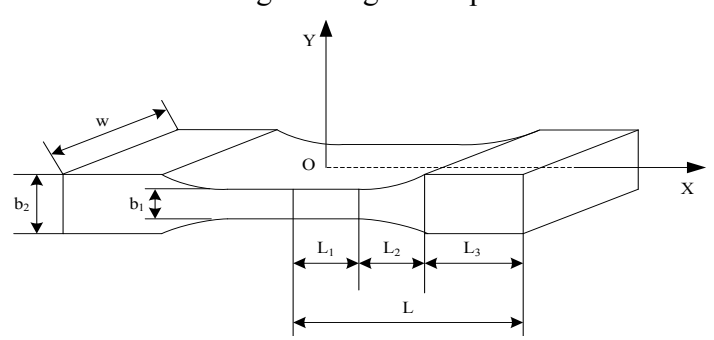

Fig.1d. Thin-plate specimen

1.1. The analytical solution of resonant length $L$ of constant cross-section specimen in Fig.1a is as follows:

$$
L=\frac{1}{2 f} \sqrt{\frac{E}{\rho}}
$$

The stress distribution formation of constant cross-section specimen is: $\sigma=E \frac{\partial U(x)}{\partial x}$ and the maximum stress is $\sigma_{\max }=E k U_{0}$.

1.2. The analytical solution of resonant length $L_{2}$ of sandglass specimen in Fig. $1 \mathrm{~b}$ is as follows:

$L_{2}=\frac{1}{k} \arctan \left\{\frac{1}{k}\left[\frac{\beta}{\tanh \left(\beta L_{1}\right)}-\alpha \tanh \left(\alpha L_{1}\right)\right]\right\}$

Where, $\alpha=\frac{1}{L_{1}} \arccos h\left(\frac{R_{2}}{R_{1}}\right), \beta=\sqrt{\alpha^{2}-k^{2}}$.

The maximum stress is 


$$
\begin{aligned}
& \sigma_{\text {max }}=\left.E \frac{\partial U(x)}{\partial x}\right|_{x=0}=\beta E U_{0} \varphi\left(L_{1}, L_{2}\right), \\
& \varphi\left(L_{1}, L_{2}\right)=\frac{\cos \left(k L_{2}\right) \cosh \left(\alpha L_{1}\right)}{\sinh \left(\beta L_{1}\right)}
\end{aligned}
$$

1.3. The analytical solution of resonant length $L_{3}$ of dog-bone in Fig.1c is as follows:

$L_{3}=\frac{1}{k} \arctan \left[\frac{1+\frac{\beta}{k} \tan \left(k L_{1}\right) \tanh \left(\beta L_{2}\right)}{\tan \left(k L_{1}\right)+\frac{k}{\beta} \tanh \left(\beta L_{2}\right)}-\frac{\alpha}{k} \tanh \left(\alpha L_{2}\right)\right]$ (6)

Where, $k=\frac{\omega}{c}, \quad c=\sqrt{\frac{E}{\rho}}, \quad \omega=2 \pi f$, $\alpha=\frac{1}{L_{2}} \operatorname{arccosh}\left(\frac{R_{2}}{R_{1}}\right), \quad \beta=\sqrt{\alpha^{2}-k^{2}}$

The maximum stress is: $\sigma_{\max }=E \beta k \varphi\left(L_{1}, L_{2}, L_{3}\right) U_{0}$

Where,

$\varphi\left(L_{1}, L_{2}, L_{3}\right)=\frac{\cos \left(k L_{3}\right) \cosh \left(\alpha L_{2}\right)}{\beta \sin \left(k L_{1}\right) \cosh \left(\beta L_{2}\right)+k \cos \left(k L_{1}\right) \sinh \left(\beta L_{2}\right)}$

1.4. The analytical solution of resonant length $L_{3}$ of thin-plate specimen in Fig. 1d is as follows:

$\left\{\alpha_{1}=\frac{1}{2 L_{2}} \ln \left(\frac{b_{2}}{b_{1}}\right), \beta_{1}=\sqrt{\alpha_{1}^{2}-k^{2}}\right.$

$\varphi\left(L_{1}, L_{2}, L_{3}\right)=\frac{\cos \left(k L_{3}\right) \exp \left(\alpha_{1} L_{2}\right)}{\left[\alpha_{1} \sin \left(k L_{1}\right)+k \cos \left(k L_{1}\right)\right] \sinh \left(\beta_{1} L_{2}\right)+\beta_{1} \sin \left(k L_{1}\right) \cosh \left(\beta_{1} L_{2}\right)}$

Where,

$L_{3}=\frac{1}{k} \arctan \left\{\frac{\cos \left(k L_{1}\right)\left[\beta_{1} \cosh \left(\beta_{1} L_{2}\right)-\alpha_{1} \sinh \left(\beta_{1} L_{2}\right)\right]-k \sin \left(k L_{1}\right) \sinh \left(\beta_{1} L_{2}\right)}{\left[\alpha_{1} \sin \left(k L_{1}\right)+k \cos \left(k L_{1}\right)\right] \sinh \left(\beta_{1} L_{2}\right)+\beta_{1} \sin \left(k L_{1}\right) \cosh \left(\beta_{1} L_{2}\right)}\right\}$

The maximum stress is

$\sigma_{\max }=E \beta_{1} \varphi\left(L_{1}, L_{2}, L_{3}\right) k U_{0}$

The control software of the commercial ultrasonic fatigue testing machine USF-2000 contains only sandglass specimen. Nevertheless, the stress amplitude of other shape specimen can be converted to the stress amplitude of the sandglass specimen according to the principle of the ultrasonic fatigue testing machine ${ }^{[10]}$. For example, the stress amplitude of thin-plate specimen in Fig.1d can be converted via Eq.(11):

$$
\sigma_{\max }^{0}=\beta \varphi_{0}\left(L_{1}^{0}, L_{2}^{0}\right) \frac{\sigma_{\max }}{\beta_{1} \varphi\left(L_{1}, L_{2}, L_{3}\right) k}
$$

Where, $\sigma_{\max }$ is stress amplitude of thin-plate specimen, $\sigma_{\max }^{0}$ is stress amplitude of sandglass specimen under the same displacement amplitude condition.

\section{The effect of the specimen shape and size}

\subsection{The effect of specimen shape}

In order to investigate the effect of specimen shape on the ultrasonic fatigue test results, the same low carbon steel are processed into thin-plate specimen and sandglass specimen respectively, shown in Fig.2. The minimum thickness of the plate is $3 \mathrm{~mm}$ and the minimum diameter of the sandglass specimen is also $3 \mathrm{~mm}$. The comparing test results are shown in Fig.3. Fig.3 shows that the fatigue lifetime of the sandglass specimen is much longer than thin-plate specimen under the same stress amplitude condition.
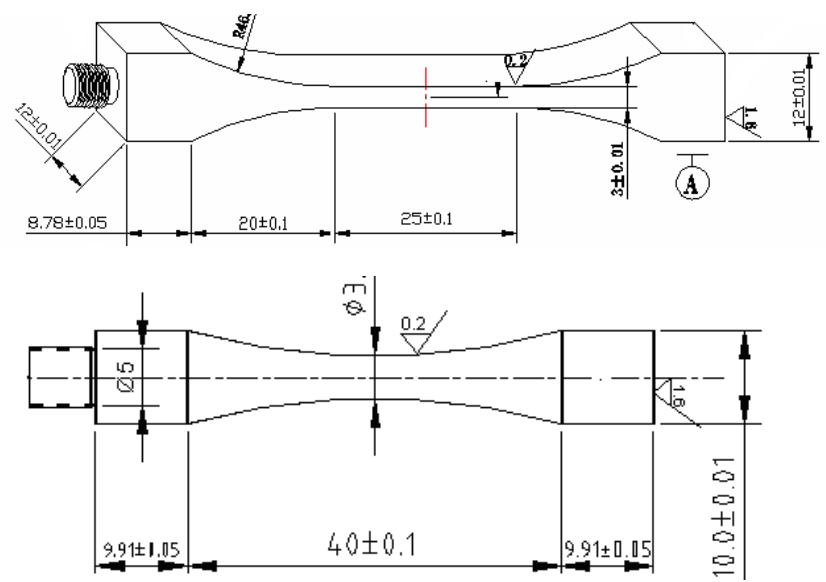

Fig.2. Thin-plate and sandglass specimen for comparing test

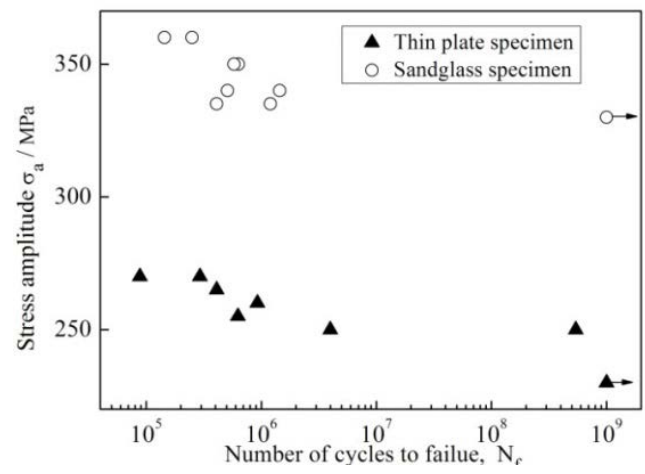

Fig.3.Test result of thin-plate and sandglass specimen

Dog-bone specimen and sandglass specimen of the same material shown in Fig.4 are also compared. The minimum diameter of the dog-bone specimen and the sandglass specimen are both $3 \mathrm{~mm}$. The comparing test results are shown in Fig.5. Fig.5 shows that the fatigue lifetime of the sandglass specimen is much longer than dog-bone specimen under the same stress amplitude 
condition.
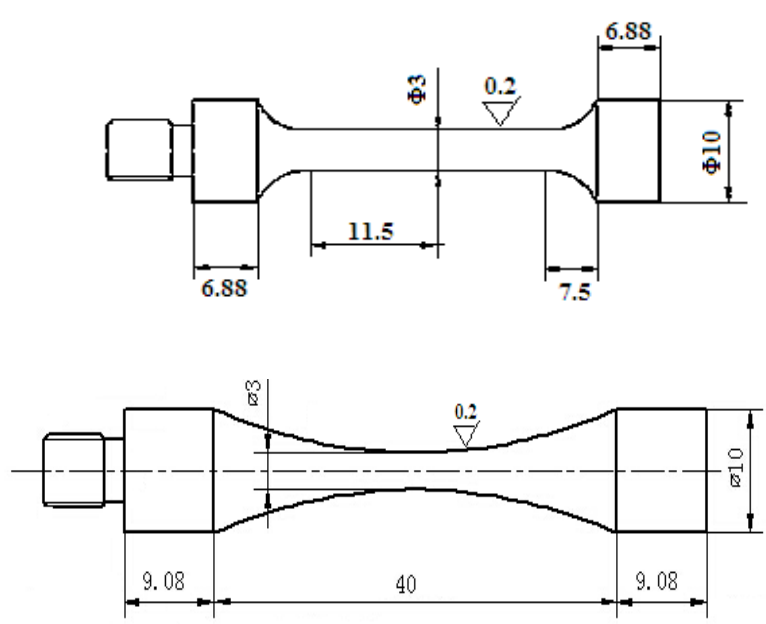

Fig.4. Dog-bone and sandglass specimen for comparing test

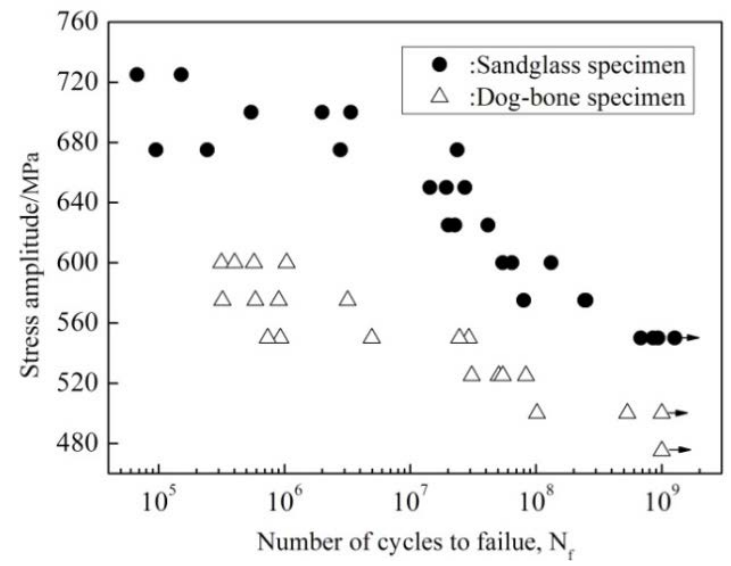

Fig.5. Test result of dog-bone and sandglass specimen

\subsection{The effect of specimen size}

In order to investigate the size effect on the ultrasonic fatigue property, ultrasonic fatigue tests are conducted on two sandglass specimen as shown in Fig.6 and the test results are compared. A specimen and B specimen have the same minimum cross-sectional area. However, the transition arc length of A specimen is longer than B specimen.

The comparing test results are shown in Fig.7. Fig.7 shows that for the low cycle region, the difference is not obvious. However for high cycle and very high cycle region, the lifetime of $\mathrm{A}$ specimen is shorter than $\mathrm{B}$ specimen under the same stress amplitude condition. Besides, the fatigue limit of the A specimen is lower than B specimen.

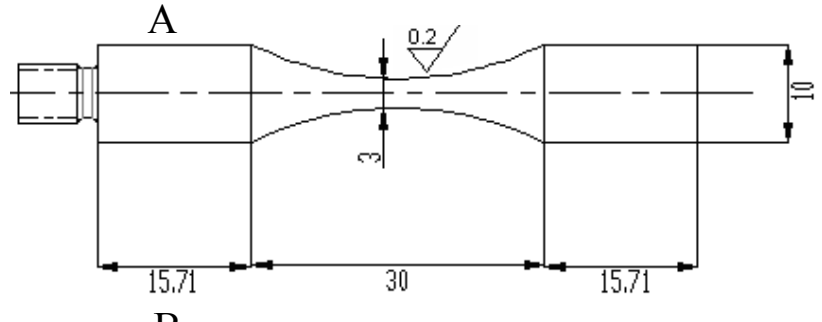

B

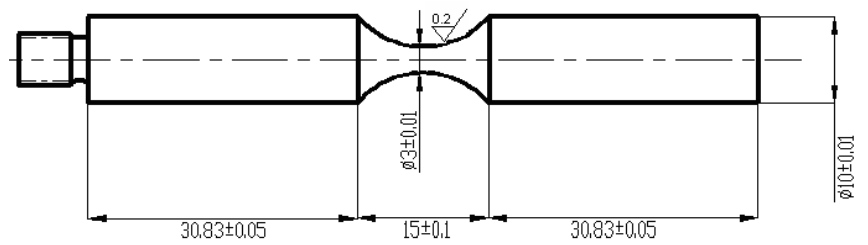

Fig.6. Sandglass specimen of different sizes for comparing

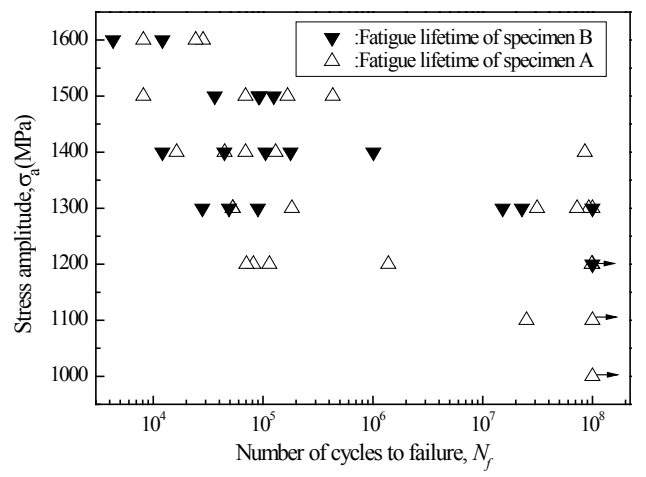

Fig.7. Test result of A and B type specimen

Another couple of sandglass specimens shown in Fig. 8 are compared additionally. The minimum diameter of $\mathrm{C}$ specimen is $3 \mathrm{~mm}$ and the surface roughness is $0.5 \mu \mathrm{m}$. The minimum diameter of $\mathrm{D}$ specimen is $5 \mathrm{~mm}$ and the surface roughness is $0.2 \mu \mathrm{m}$. The comparing test results are shown in Fig.9. Fig.9 shows that although the surface roughness of $\mathrm{C}$ specimen is larger than $\mathrm{D}$, the fatigue lifetime of $\mathrm{C}$ specimen is much longer than $\mathrm{D}$ specimen under the same stress amplitude condition as $\mathrm{C}$ specimen has less minimum diameter.
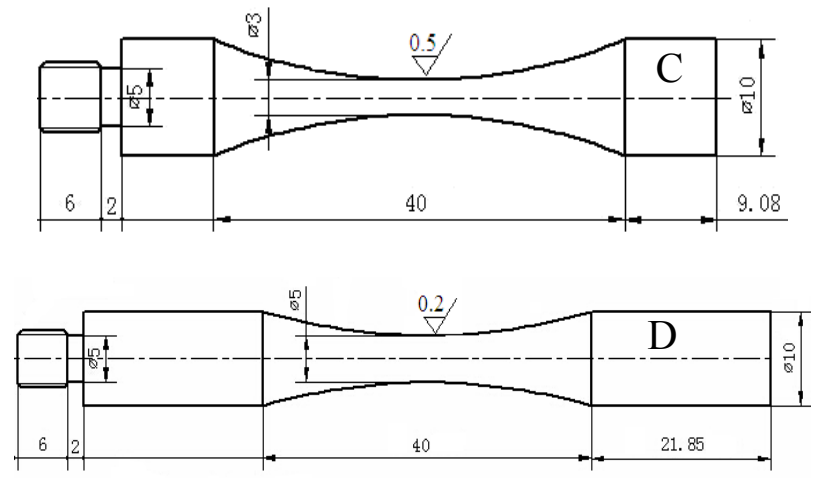

Fig.8. Sandglass specimen of different sizes for comparing 


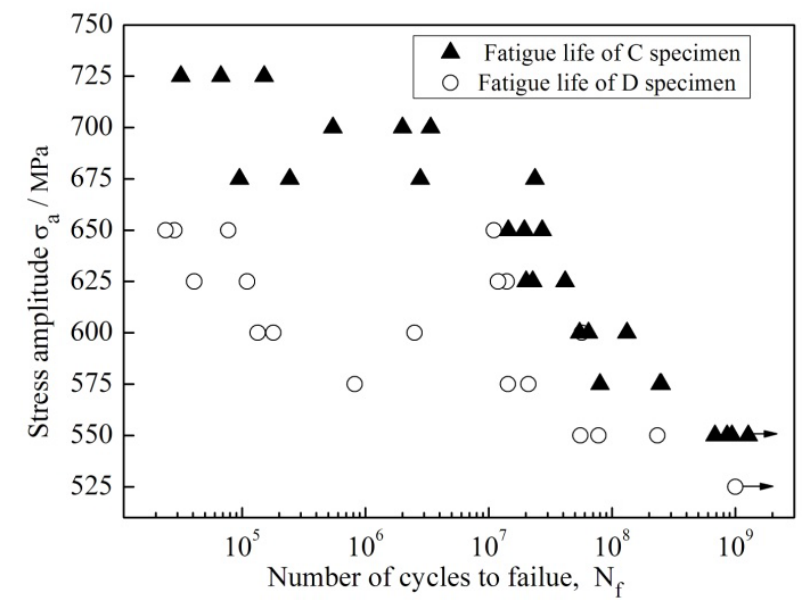

Fig.9. Comparison of the test result of $\mathrm{C}$ and $\mathrm{D}$ type specimen

It can be seen from Fig.3、Fig.5、Fig.7 and Fig.9 that the specimen shape and size affect the VHCF test results obviously, especially from Fig.3, Fig.5 and Fig.7. This is due to different risk volume which is estimated as the part of the specimen subjected to above $90 \%$ of the maximal stress ${ }^{[11-12]}$. LCF and HCF cracks mostly initiated from surface as the relatively high loading stress, hence, LCF and $\mathrm{HCF}$ are processes of finding defects from the surface. However, VHCF is a process of finding large defects inside the specimen volume ${ }^{[13]}$. The probability of large defects being present is likely to increase in response to the increase of the risk volume. As a result, VHCF is more sensitive to specimen size than LCF and HCF.

\section{The effect of the specimen surface roughness}

The specimen surface roughness is not only an influential factor on the $\mathrm{HCF}$ testing results, but also an influential factor on the $\mathrm{VHCF}^{[14]}$. If the roughness is too large, the fatigue strength will be dominated by surface roughness. However, if the roughness is reduced to a certain critical value, the surface can be considered to be "smooth". The formula of the critical value is expressed as ${ }^{[15]}$ :

$$
a_{\mathrm{s}} \approx k\left(1+\frac{120}{\mathrm{HV}}\right)^{6}, k=0.171
$$

Eq.(12) express the theoretical critical value of the surface roughness. The coefficient $k$ are modified according to test results in the present paper:

$$
a_{\mathrm{s}} \approx k\left(1+\frac{120}{\mathrm{HV}}\right)^{6}, k=0.08
$$

It can be seen from Eq.(12) and Eq.(13), as the specimen material hardness or strength increases, the threshold becomes smaller. In other words, higher strength material requires lower roughness for $\mathrm{VHCF}$ testing.

In order to validate Eq.(13), a high strength steel $(\mathrm{HV}=380)$ is processed into sandglass specimens with the same size and different surface roughness. The critical roughness value is $0.42 \mu \mathrm{m}$ according to Eq.(13). The surface roughnesses of $\mathrm{E}$ group specimen are around $0.3 \mu \mathrm{m}$ and the surface roughnesses of $\mathrm{F}$ group specimen are around $0.74 \mu \mathrm{m}$.

The VHCF results are shown in Fig.10. It can be seen that as the roughness of $\mathrm{F}$ group $0.74 \mu \mathrm{m}$ is much larger than the critical value $0.42 \mu \mathrm{m}$, the fatigue lifetime of $\mathrm{F}$ group specimen is lower than $\mathrm{E}$ group at the same stress amplitude condition. Besides, only 2 specimens of F group fracture at very high cycle region, i.e. beyond $10^{7}$ cycles, and only 3 specimens fracture from interior. The test results of $\mathrm{F}$ group are dominated by surface roughness and the larger roughness lead to premature fracture from surface. However, for $\mathrm{E}$ group, 11 specimens of fracture at very high cycle region and 13 specimens fracture from interior. The test results of $\mathrm{F}$ group are dominated by internal defects.

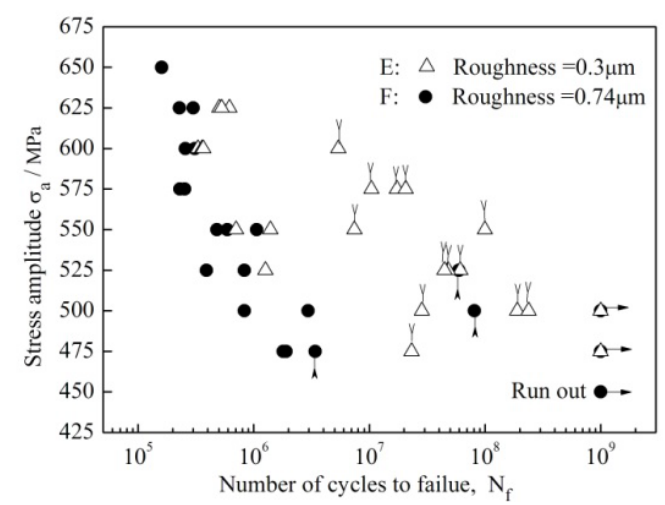

Fig.10. Test result of $\mathrm{E}$ and $\mathrm{F}$ group specimen (The vertical arrow denotes interior-initiated fracture)

\section{The effect of the inclusion size}

It can be know from above that VHCF usually fractured from interior and is dominated by internal defects. At the fatigue process, the surface defects (such as PSB or machining marks) and internal defects (such as inclusion) are a competition relation. When the applied loading is relatively high and the inclusion size is relatively small, the specimen tends to LCF from surface. 
When the applied loading is relatively low, the specimen tends to VHCF from interior. When the applied loading is relatively high and the inclusion size is relatively large, the specimen either tends to VHCF from interior or tends to LCF from surface. Based on this, the relationship of $S / N$ curve and inclusion size can be analyzed as below.

Case 1: The inclusion size $\phi$ is less than a certain critical value $\phi_{\mathrm{inc}}^{\mathrm{min}}$. As the inclusion size is small enough, it does not affect the fatigue. At relatively low stress, the specimen will not fracture at very high cycle region. Therefore, the specimen either tends to fracture from surface at low cycle or high cycle region under high stress, or not fracture under low stress. The $S / N$ curve character is indicated as the 1 type $S / N$ curve in Fig. 11.

Case 2: The inclusion size $\phi$ is large than the certain critical value $\phi_{\text {inc }}^{\min }$, however, less than a certain critical value $\phi_{\mathrm{inc}}^{\max }$. The specimen fractured from surface at high stress. However, when the stress descends to a certain level, the surface crack of the specimen will be in balance with the internal crack competition. Therefore, the specimen either tends to LCF fracture from surface or VHCF fracture from interior inclusion at the balance stress. Thus, the $S / N$ curve exhibits a horizontal line and the length of the horizontal line increases as the inclusion size descends. Then the $S / N$ curve continuously descends at lower stresses as shown as the 2 type $S / N$ in Fig.11.

Case 3: The inclusion size $\phi$ is large than a certain critical value $\phi_{\mathrm{inc}}^{\max }$. As the inclusion size is large enough, the specimen will still fracture from the large inclusions at low stresses. As a result, the $S / N$ curve exhibits a continuously descending shape and the horizontal asymptote is not obvious, as indicated as the 3 type $S / N$ curve in Fig.11.

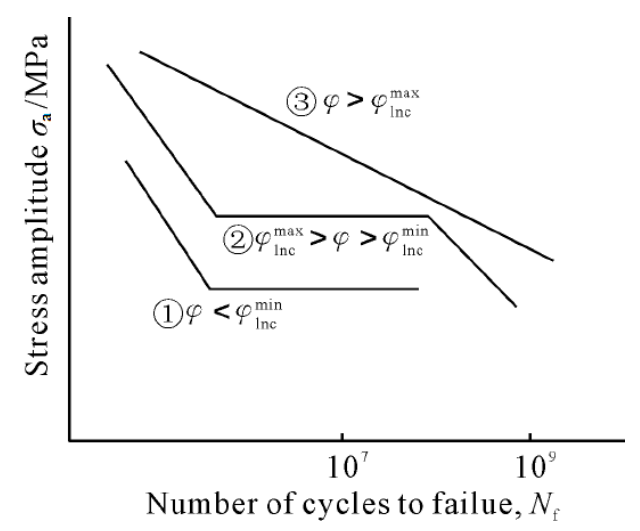

Fig.11. The relation of the $S / N$ character and the inclusion size
For high strength steel, $\phi_{\mathrm{inc}}^{\max }$ is $20 \mu \mathrm{m}^{[15]}$. Assuming the inclusion shape is spherical, the critical value $\phi_{\mathrm{inc}}^{\mathrm{min}}$ is calculated by using the following equation ${ }^{[15]}$

$$
\phi_{\text {inc }}^{\min }=C_{\text {in }}\left(1+\frac{120}{\mathrm{HV}}\right)^{6}
$$

In which, $C_{\text {in }}$ is a coefficient related with the location of the inclusion. $C_{\text {in }}$ is $0.813,0.528,0.969$ respectively, when the inclusion is located at the surface, sub-surface and interior as shown in Fig.12. In Fig.12, when the inclusion is located at the sub-surface, the competition between surface defects and internal defects turns into a cooperative relationship to jointly promote the production of fatigue crack, as a result, $C_{\mathrm{in}}$ is the least at this case.

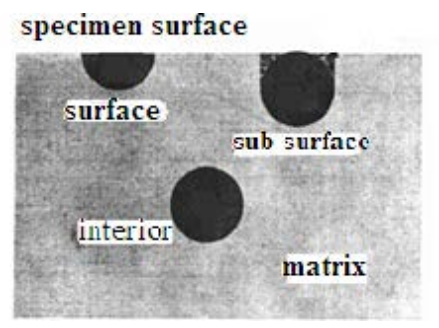

Fig.12. The locations of inclusion or defect in specimen

In order to validate the relationship of $S / N$ curve and inclusion size analyzed above, VHCF $S / N$ curve of a high strength steel is tested in this paper. The fracture surfaces of the fatigued sandglass specimen are scanned via SEM as shown in Fig.13a and the inclusion sizes are measured. The average of all the measured inclusion size $\phi$ is about $14.2 \mu \mathrm{m}$. The critical value $\phi_{\text {inc }}^{\min }$ of the high strength steel is about $4.5 \mu \mathrm{m}$ according to Eq.(14). The average inclusion size is larger than the critical value $\phi_{\text {inc }}^{\min }$ and less than the critical value $\phi_{\text {inc }}^{\max }$, thus the $S / N$ curve can be predicted to be the 2 type $\mathrm{S} / \mathrm{N}$ in Fig.11. The prediction is validated through the tested $S / N$ curve as shown in Fig.13b.

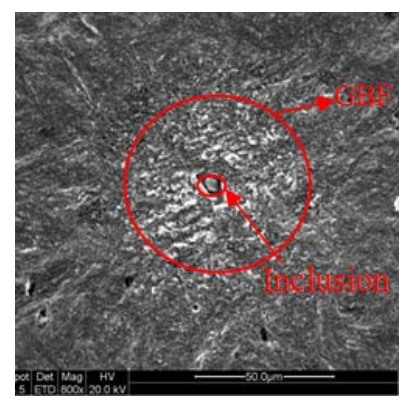

Fig.13a. A typical VHCF surface $\left(N_{f}=1.86 \times 10^{8}\right)$ 


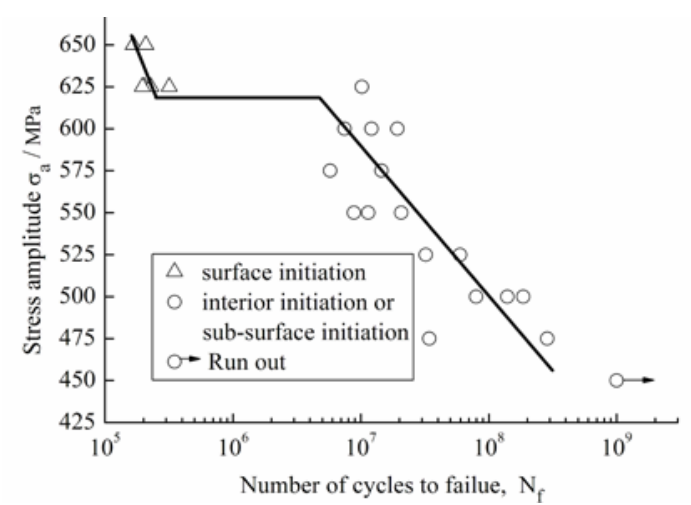

Fig.13b. The tested VHCF $S / N$ curve of a high strength steel

\section{Loading frequency effect}

The very high frequency $20 \mathrm{kHz}$ would cause a drastic change of the fatigue behavior comparing with the usual frequency ${ }^{[17-18]}$. The change of loading frequency affects the test results through changing the strain rate. For specimens with the same size, the fatigue life tends to increase with an increase of the fatigue loading frequency as shown in Fig. 14.

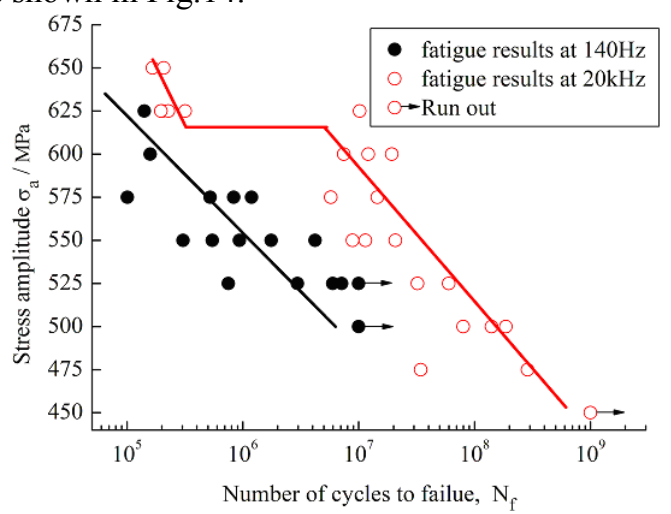

Fig.14. Fatigue test results of a high strength steel at $140 \mathrm{~Hz}$ and $20 \mathrm{kHz}$

Assuming the dislocations move freely, according to Johnston-Gilman ${ }^{[19]}$, the distance a travels in dislocation a quarter of cycle is:

$L=\int_{0}^{\text {cycle } / 4} v \mathrm{~d} t=\frac{A\left(n \sigma_{0}\right)^{m}}{2 \pi f} \exp \left(-\frac{Q}{k T}\right) \int_{0}^{\pi / 2}(\sin \chi)^{m} \mathrm{~d} \chi \propto \frac{1}{f}$

$Q$ is the activation energy for dislocation, $k$ is Boltzmann constant, $A$ and $m$ material constant, $T$ is absolute temperature.

It is seen from Eq.(15) that the distance the dislocation travels decreases as the loading frequency increases. As a result, the fatigue life tends to increase with an increase of the fatigue loading frequency. The calculation is taken under the assumption that dislocations move freely. Practically for very high strength steel or alloy steel, there are a lot of obstacles such as fixed dislocations and grain boundary in materials and they will shorten the moving distance markedly. Hence the effect of load frequency may be very small or vanish in very high strength steels or alloy steel. This fact has been supported by author ${ }^{[20]}$ and many other experiments ${ }^{[21-26]}$.

Thus, the ultrasonic test results of very high strength steel or alloy steel can be used for practical. However, for low carbon steels, sensitive to the loading frequency, applying the ultrasonic test results directly will lead to unsafe results. The ultrasonic test results should be modified before applying. Wang $\mathrm{H}^{[27]}$ used a modifying coefficient of load frequency to describe the effect of load frequency on fatigue behavior in ultrasonic fatigue testing. The modifying coefficient equals the ratio of fatigue strength coefficient of lower frequency load and high frequency load. Recently, Benjamin\&Akira ${ }^{[28-29]}$ point that $S / N$ properties under usual frequencies of $0.2 \sim 140 \mathrm{~Hz}$ can be successfully normalized by the lower yield stress at the individual frequency. However, the $S / N$ curve cannot be normalized as the same way for $20 \mathrm{kHz}$ as shown in Fig.15 as the crack initiation mode has been changed at $20 \mathrm{kHz}$. So modifying the test results at $20 \mathrm{kHz}$ is a not easy thing as the mechanism of frequency effect should considered thoroughly and deeply.

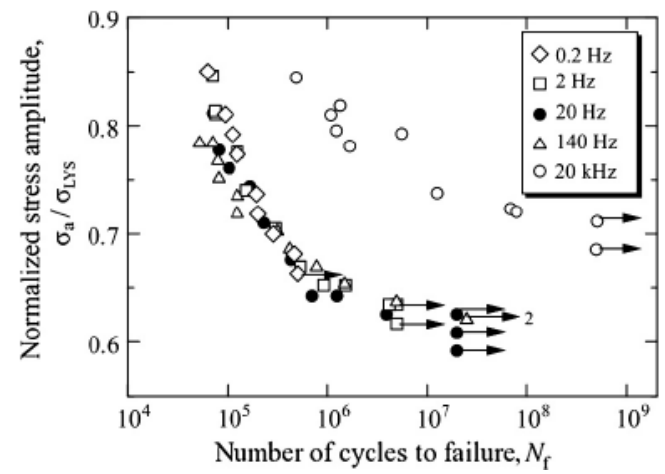

Fig.15.Normalized $S / N$ curve by yield stress ${ }^{[28-29]}$

\section{Conclusions}

Fatigue tests of hundreds of specimen are conducted to investigate the effect of specimen shape, size, surface roughness, inclusion size and load frequency on the VHCF testing results. The following conclusions are dawn:

1. The fatigue test results differ for different specimen shape and size, as the risk volume differs. Furthermore, VHCF is more sensitive to specimen size than LCF and 
HCF.

2. There is a critical roughness for the specimen, depending on the hardness of tested metallic material. A larger roughness than the critical one will lead to a premature fracture due to the surface defects and test result can not reveal the internal defects character.

3. The VHCF region is dominated by the internal defects for high strength steel and the VHCF $S / N$ curve character is strongly related to the size of the inclusion. Thus, the inclusion size can be predicted through the VHCF $S / N$ curve.

4. The frequency effect can be ignored for very high strength steel or alloy steel. However for low carbon steel, the fatigue life tends to increase as the loading frequency increases. Hence, the test results should be modified before used for practical. The modifying should be based on mechanism of frequency effect and it needs further research.

\section{References}

1. Marines I, Bin X, Bathias C. An understanding of very high cycle fatigue of metals. Int.J.Fatigue, 25(9-11),1101-7(2013)

2. Miller KJ, O'Donnell WJ. The fatigue limit and its elimination. Fatigue Fract Eng Mater Struct,7, 545-57(1999)

3. Bathias C, Drouillac L, Le Francois P. How and why the fatigue S-N curve does not approach a horizontal asymptote. Int.J.Fatigue, 23,143-51(2001)

4. Murakami Y, Nomoto T, Ueda T. On the mechanism of fatigue failure in the super long life regime $\left(\mathrm{N}>10^{7}\right.$ cycles). Part I: influence of hydrogen trapped by inclusions. Fatigue Fract Eng Mater Struct, 11,893-902(2000)

5. Mason W P. Piezoelectric crystals and their application in Ultrasonic. (New York: Van Nostrand, 1950)

6. Bathias C. Piezoelectric fatigue testing machines and devices. Int.J.Fatigue, 28,1438-1445(2006)

7. Stanzl-Tchegg SE. Fracture mechanisms and fracture mechanics at ultrasonic frequencies. Fatigue Fract Eng Mater Struct,22(7),567-79(1999)

8. Wang QY, Berard JY, Dubarre A, Baudry G, Rathery $\mathrm{S}$, Bathias C. Gigacycle fatigue of ferrousalloys.Fatigue Fract Eng Mater
Struct,8,667-72(1999)

9. Xue Hongqian, et.al. The design of specimen for fatigue test at ultrasonic frequency. Acta Aeronautics et Astronautics sinica,25(4),425-428(2004)

10. Peng WJ, et.al. Ultrasonic fatigue test method of several kinds specimen. Journal of Wuhan Engineering Institute, 28(2),1-4(2016)

11. Y. Furuya. Specimen size effects on gigacycle fatigue properties of high-strength steel under ultrasonic fatigue testing. Script Materialia,58, 1014-1017(2008)

12. Y. Furuya, et al. $10^{10}$-cycle fatigue properties of 1800MPa-class JIS-SUP7 spring steel. Fatigue Fract Engng Mater Struc,26,641-645(2003)

13. B. Pyttel, D. Schwerdt, C. Berger. Very high cycle fatigue - Is there a fatigue limit? Int.J.Fatigue, 33,49-58(2011)

14. H. Itoga, K. Tokaji, M. Nakajima, H.-N. Ko. Effect of surface roughness on step-wise $\mathrm{S}-\mathrm{N}$ characteristics in high strength steel. Int.J.Fatigue, 25,379-385(2003)

15. Yang Zhenguo, et.al. Estimation of the critical size of inclusion in high strength steel under high cycle fatigue condition. Acta metallurgica sinica, 41(11),1136-1142(2005)

16. Yang Zhenguo, et.al. On the critical inclusion size of high strength steel under ultra-high cycle fatigue. Mater Sci Eng A, 2006, 427A, 167-174(2006)

17. Peng WJ, et.al. Ultrasonic fatigue tests on a high strength steel for welded structure. Advanced Materials Research, 503-504 :714-717 (2012)

18. Isamu Nonaka, Sota Setowaki, Yuji Ichikawa. Effect of load frequency on high cycle fatigue strength of bullet train axle steel. Int.J.Fatigue, 60(1),43-47(2014)

19. Zhang Yangyang, Duan Zheng, Shi HuiJi. Comparison of the very high cycle fatigue behaviors of INCONEL 718 with different loading frequencies. Science China Physics, Mechanics and Astronomy,56(3),617-623 (2013)

20. Peng WJ, et.al. An investigation of the fatigue property of ultra-high strength mould steel at $130 \mathrm{~Hz}$ and $20 \mathrm{kHz}$.Applied Mechanics and Materials, 239-240, 96-99 (2013)

21. Aiguo Zhao, et.al. Effects of strength level and 
loading frequency on very-high-cycle fatigue behavior for a bearing steel. Int.J.Fatigue, 38,46-56(2012)

22. I.Marines, et.al. Ultrasonic fatigue tests on bearing steel AISI-SAE 52100 at frequency of 20 and 30 kHz. Int.J.Fatigue,25,1037-1046(2003)

23. Y. Furuya, S. Matsuoka, T. Abe, K. Yamaguchi. Gigacycle fatigue properties for high-strength low-alloy steel at $100 \mathrm{~Hz}, 600 \mathrm{~Hz}$, and $20 \mathrm{kHz}$. Scripta Materialia,46,157-162(2002)

24. H. Mayer, M. Papakyriacou, R. Pippan, S. Stanzl-Tschegg. Influence of loading frequency on the high cycle fatigue propertiesof $\mathrm{AlZnMgCu} 1.5$ aluminium alloy.Materials Science and Engineering A ,314,48-54(2001)

25. Stanzl-Tschegg SE, Mayer H. Fatigue and fatigue crack growth of aluminium alloys at very high numbers of cycles. Int.J.Fatigue,23,231-237(2001)

26. Chen Q, et. al. Small crack behavior and fracture of nickel-based super alloy under ultrasonic fatigue. Int.J.Fatigue, 10,1227-32(2005)

27. Wang Hong, Gao Qing. Effect of load frequency on fatigue behavior of material in ultrasonic fatigue testing. PTCA (Part: A PHYS.TEST), 41(9),433-435(2005)

28. Benjamin Guennec, et.al. Effect of the loading frequency on fatigue properties of JIS S15C low carbon steel and some discussions based on micro-plasticity behavior. Int.J.Fatigue,2014,66, 29-38(2014)

29. Benjamin Guennec, et.al. Dislocation-based interpretation on the effect of the loading frequency on the fatigue properties of JIS S15C low carbon steel. Int.J.Fatigue, 70, 328-341(2015) 